\title{
The Neurophysiological Substrate of the Decision-Making Process in Depressed Patients
}

\author{
Silvia Gomes Laurentino ${ }^{*}$, Sandra Lopes de Souza², Everton Botelho Sougey ${ }^{2}$ \\ ${ }^{1}$ Post Graduate Program of Neuropsychiatry and Behavioral Sciences, Federal University of Pernambuco, Recife, Brazil \\ ${ }^{2}$ Department of Neuropsychiatry, Federal University of Pernambuco, Recife, Brazil \\ Email: *silvialaurentino@gmail.com
}

How to cite this paper: Laurentino, S. G., de Souza, S. L., \& Sougey, E. B. (2020). The Neurophysiological Substrate of the Decision-Making Process in Depressed Patients. Open Journal of Depression, 9, 43-57. https://doi.org/10.4236/ojd.2020.93005

Received: May 31, 2020

Accepted: July 31, 2020

Published: August 3, 2020

Copyright $\odot 2020$ by author(s) and Scientific Research Publishing Inc. This work is licensed under the Creative Commons Attribution International License (CC BY 4.0).

http://creativecommons.org/licenses/by/4.0/

\begin{abstract}
Background: The neural circuits involved in the decision-making process and social emotion participate in the same circuits seen in major depressive disorder. This study aimed to investigate in depressed patients, the decision making process in risk/reward situations using neurophysiological methods for a better assessment of functional aspects related to decision making deficit that are seen in major depression. Methods: Forty patients were studied, 20 with depression and 20 without. After applied the Structured Clinical Interview for DSM-IV Axis I Disorders (SCID-I) and Hamilton Depression scale (HAM-D), the Iowa Gambling Task (IGT) was applied to analyze the risk/ reward decision-making behavior. The Skin Conductance Response (SCR) was recorded to analyze the emotional anticipatory learning effect during the IGT. Besides, an EEG was recorded to measure the Frontal Alpha Asymmetry Index (FAAI). Results: Depressed patients presented a lower Net score and a deficit in anticipatory learning effect in the IGT. Furthermore, the FAAI revealed more frontal right activation as have described in previous studies. Conclusion: Patients with major depression have a dysfunction in the circuits that modulate cognitive, emotional and social behavior, and also, impairment in cognitive fluidity for evaluating strategies for risk-reward. The EEG helps to confirm that asymmetry in frontal areas and oscillation of alpha frequencies participate in the regulation of emotion in depressed patients.
\end{abstract}

\section{Keywords}

Major Depression, Decision Making, Iowa Gambling Task, Somatic Marker, Skin Conductance Response, EEG 


\section{Introduction}

Depressive disorders affect around a fifth of the world population at some time in their lives (Barger, Messerli-Burgy, \& Barth, 2014; Gavin et al., 2010) and, it may seriously impair the performance of everyday and work-related activities (Barger et al., 2014; Cusi, Nazarov, Holshausen, Macqueen, \& McKinnon, 2012). One of the less well-known and under-investigated symptoms of depression, and one that causes the most serious social and economic problems, is indecision (Harle, Allen, \& Sanfey, 2010; McLaughlin, 2011; Pizzagalli, Iosifescu, Hallett, Ratner, \& Fava, 2008; Radford, Nakane, Ohta, Mann, \& Kalucy, 1991). People with depression may experience difficulty in making decisions as a result of various factors, such as impaired concentration, a negative outlook, and diminished motivation and self-confidence (Harle et al., 2010; van Randenborgh, de Jong-Meyer, \& Huffmeier, 2010; Zhang, Sun, \& Lee, 2012). Because of this, there has been growing interest in studying the neurocircuits involved in models of mood disorder (Drevets, 1999, 2003, 2007; Drevets \& Raichle, 1992) and in the neural bases of social cognition. There is thus a need to understand and conduct a more in-depth study of depression and its relation to decision-making (Costello, 1983; Cusi et al., 2012; Fellows \& Farah, 2007; Henriques, Glowacki, \& Davidson, 1994; Holmes \& Pizzagalli, 2008; Pizzagalli, 2011).

The neuro-anatomical substrate involved in the decision-making process (analysis in situations of certainty, cost-benefit analysis in situations of uncertainty) may have various routes in common with those found in neurocircuit dysfunctions observed in depressed individuals (Fellows \& Farah, 2007; Harle et al., 2010; Holmes \& Pizzagalli, 2008; Radford et al., 1991; Takahashi et al., 2008). These processes are all interlinked and involve areas or circuits related to the pre-frontal cortex (Bechara, Damasio, Tranel, \& Damasio, 2005; Beitz, Salthouse, \& Davis, 2014; Cotrena et al., 2014; Cui, Chen, Wang, Shum, \& Chan, 2013; Greene, Nystrom, Engell, Darley, \& Cohen, 2004; Greene \& Paxton, 2009; Li, Lu, D’Argembeau, Ng, \& Bechara, 2010; Steingroever \& Wagenmakers, 2014; Takahashi et al., 2008). Studies using the Iowa Gambling Task (IGT), a card game that evaluates decision-making by simulating gains and losses in a situation of uncertainty (punishment/reward) reveal that patients who are depressed and/or apathetic show greater impulsiveness and are less effective in performing the tasks (Bechara et al., 2005; Bollon \& Bagneux, 2013; Jaracz \& Borkowska, 2012).

\subsection{Neural Circuits Involved in Major Depression}

Studies of neuroimaging, neurophysiology, and neuropathology have shown that the neural network that modulates emotional behavior is, generally, also involved in the physiopathology of mood disorders. The main circuit involved in emotional behavior and major depression is the limbic-cortical-striatal-pallidalthalamic circuit (LCSPTC), formed by connections with the orbitofrontal cortex (OFC), amygdala, hippocampus, subiculum, ventromedial striatum, medial and medial dorsal thalamic nuclei and the ventral pallidum (Drevets, 2001, 2007; Drevets, Price, \& Furey, 2008; Ongur, Ferry, \& Price, 2003). One of the most 
important connections with the LCSPTC concerns the areas of the brain responsible for visceral control, especially the hypothalamus and the periaqueductal gray matter (PGM) (Nauta \& Domesick, 1984; Price, 2007). A second visceromotor circuit identified in the physiopathology of depression involves the subgenual anterior cingulate cortex ( $\mathrm{sgACC}$ ), amygdala, and ventral striatum route. The pathological activity of this circuit seems to be suppressed when exposed to pharmacological, surgical, or deep brain stimulation treatment for major depression (Drevets, 2003; Drevets, Bogers, \& Raichle, 2002; Drevets, Savitz, \& Trimble, 2008).

\subsection{Electrophysiological Alterations in Major Depression}

Neurophysiological studies have also been used to provide a better understanding of the circuits involved in major depression (Coan, Allen, \& McKnight, 2006; Davidson, Chapman, Chapman, \& Henriques, 1990; Henriques \& Davidson, 1991; Pizzagalli, Peccoralo, Davidson, \& Cohen, 2006; Schaffer, Davidson, \& Saron, 1983; Stewart, Bismark, Towers, Coan, \& Allen, 2010; Stewart, Coan, Towers, \& Allen, 2011). The main electrophysiological variable used to study mood disorders is the Frontal Alpha Asymmetry Index and this is considered a predictive factor for depression (Davidson, 1998; Henriques \& Davidson, 1991; Schaffer et al., 1983; Stewart et al., 2010; Stewart et al., 2011).

Studies with depressed, or previously depressed, patients have shown more alpha activity in the left frontal cortex, this being inversely proportional to cortical activity (Allen \& Kline, 2004; Davidson, 1992; Henriques \& Davidson, 1990, 1991; Stewart et al., 2010; Tomarken, Davidson, Wheeler, \& Doss, 1992; Zoon et al., 2013). Frontal alpha asymmetry has been related to the value dimension of emotion, with negatively valued emotions being more associated with activation of the right frontal cortex, while positive emotions are associated with activation of the left (Tomarken, Davidson, \& Henriques, 1990). It should be pointed out that not only the value dimension of emotion (negative or positive) but also the direction (attraction or repulsion) lie at the root of frontal alpha asymmetry (Harmon-Jones \& Allen, 1997, 1998; Sutton \& Davidson, 2000).

\subsection{Decision-Making in Major Depression}

As decision-making is a process involving preference, selection and execution of actions, and evaluation of results, various brain circuits are interlinked in this complex system (Levin et al., 2012). Neuroimaging studies using brain fMRI and PETscan show that the areas involved in the decision-making circuit include the dorsolateral and ventromedial prefrontal cortex, the amygdala, the parietal and temporal cortex, the parahippocampal region and the anterior cingulate gyrus (75). In other words, all the regions that are functionally involved in social behavior and the regulation of emotion.

\subsection{Punishment/Reward-Type Decision-Making}

Damásio et al. postulated that patients with lesions in the ventromedial prefron- 
tal cortex were incapable of using emotion took make appropriate decisions and building up the so-called somatic marker hypothesis. This concept came from the idea that emotion is a fundamental component in guiding decision-making in situations where the result of a choice, in terms of punishment or reward, was uncertain (Bechara, Tranel, \& Damasio, 2000; Damasio, Grabowski, Frank, Galaburda, \& Damasio, 1994).

To test the somatic marker hypothesis, Bechara \& Damásio (2005) developed a test based on a simulation of real-life decision-making, the Iowa Gambling Task (IGT). The IGT provides a punishment or reward during each turn, depending on the choice of a certain card by each participant (Bechara \& Van Der Linden, 2005).

In short, the present study aims to provide more in-depth knowledge of electrophysiological and behavioral findings involved in depression and decision-making behavior.

\section{Materials and Methods}

The experiments were conducted with a cross-sectional cohort at the Applied Neuroscience Laboratory (Neurolab-Brazil), in Recife, Pernambuco in association with the Federal University of Pernambuco (UFPE) during three years from 2015.

\subsection{Participants}

Forty healthy, right-handed subjects, 20 with and 20 without major depression, participated after providing informed, written consent, following the Helsinki Declaration and local ethics committee. A senior neurologist saw all participants, who administered a carefully designed questionnaire (SCID-IV) (First, Spitzer, Gibbon, \& Williams, 1997) and (HAM-D) (Hamilton, 1960, 1967) to rule out medical conditions related to psychiatric and neurological disorders. In the non-depressed there were some inclusion criteria like having more than 12 years of schooling; be right handed; do not use any type of antidepressant at the time of the evaluation; does not have any type of injury or neurological dysfunction (traumatic brain injury, epilepsy, stroke) or psychiatric (bipolar disorder, schizophrenia, cyclothymia); do not use alcohol or use illegal drugs; do not meet the criteria for major depression of SCID-IV. For depression group there were the same inclusion criteria with exception to be included in the major depression criteria of SCID-IV. As exclusion criteria for both group it was considered the presence of excessive EEG artifacts and appearance of changes in the EEG record that suggests some type of pathological dysfunction.

\subsection{Procedures}

All participants were invited to sit comfortably in a chair facing a computer monitor. The technician explained carefully to each subject that the experiment was safe and innocuous and provided details of the procedure during the task. 


\subsubsection{Behavioral Task}

\section{Iowa Gambling Task (IGT)}

For this task participants received standard instructions for the IGT (Bechara et al., 2005). For instance, they were told that the object of the task was to win as much as possible and avoid losses by drawing cards, one at a time, from the four decks. It was explained that each card drawn would indicate that he could win or whether there was also a penalty. All patients were also advised that some decks could be more advantageous than others and that during the game they should feel free to switch from one deck to another. However, they were not informed of the schedule of wins and losses in each deck or advised on how to draw the cards.

For this task, participants were asked to select cards from any of four decks labeled A, B, C, and D. Mixture cards in each deck was presented, half with a red circle and half with blue one on the underside. Whether the patient choosing a card that had a red circle will result in a win, however choosing a card with a blue circle on the underside could result in a win but could also result in a penalty. Every card in decks A and B resulted in a \$100 win, and every card in decks $C$ and $D$ resulted in a $\$ 50$ win, but the penalties were higher when blue circle cards were drawn from decks A and B compared to decks C and D. Decks $\mathrm{C}$ and $\mathrm{D}$, therefore, resulted in greater net wins throughout the task because of the smaller penalties attached to cards with blue circles.

The performance of the IGT was evaluated by dividing the 100 cards drawn into 5 blocks of twenty, with a response time of six seconds between each card they picked. The volunteer had to choose between advantageous ( $C$ and $D)$ and disadvantageous cards ( $\mathrm{A}$ and $\mathrm{B}$ ), the final result is calculated as the total Net score. To total Netscore, first the K-S test was applied showing a parametric distribution in both groups. In this case the t-student test was used to compare the total Netscore between depressed and non-depressed groups.

Calculation of the Net score was based on the sum of the numbers of cards chosen according to the following formula $[(C+D)-(A+B)]$. The performance of the volunteers was then classified as unimpaired, impaired, or borderline. When subjects scored over 18 points $(>+18)$ the performance was considered unimpaired; for scores between $(>-18$ and $<+18)$, performance was considered borderline; and below $18(<-18)$ impaired (Denburg, Tranel, \& Bechara, 2005).

The second criterion chooses for analysis, which is commonly mentioned in the literature (Bechara et al., 2005), concerns the score per block, obtained in each of the five blocks of 20 choices (cards), in the course of the 100 choices (rounds). The equation used to obtain this result is the same one used to calculate the overall score $[(\mathrm{C}+\mathrm{D})-(\mathrm{A}+\mathrm{B})]$, applied to each block of 20 cards. This score allows researchers to ascertain whether a learning curve has been followed during the execution of the task. To study the learning curve, the Netscore per block ( 5 blocks of 20 rounds) was applied and also a K-S test showing a parametric distribution. For this reason, a repeated-measures ANOVA statistical analy- 
sis with Tukey post hoc was applied, to study the learning curve between depressed and non-depressed participants in the 100th round of the IGT task

\subsubsection{Electroencephalogram Recording}

In preparation for the EEG recording, the distance between the nasion and inion was measured to determine the electrode capsizes. The forehead and the mastoid were prepared with a mild abrasive gel to remove any oil from the skin. After fitting the cap on the scalp, each electrode site was injected with electrogel. A 32-channel bioamplifier (Nexus 32; Mind Media B.V.; Netherlands) Biotrace true-DC polygraph, which uses a fast USB 2.0 and fiber optics, offering up to 2048 samples per second on all EEG channels/24-bit resolution. The EEG recordings from the 40 subjects were acquired from a 21-channel carbon cap in which each EEG channel had its active shield, and carbon-coated cables in combination with active shielding were used to minimize $50 / 60 \mathrm{~Hz}$ noise. The channels of the cap were positioned according to the international 10 - 20 system, with linked mastoids as the recording reference (Fp1, Fp2, F3, F4, Fz, F7, F8, C3, C4, Cz, T3, T4, T5, T6, P3, P4, Pz, O1, O2, A1, A2). The EEG recordings were acquired at a sampling rate of $512 \mathrm{~Hz}$ and bandpass filtered between 1 and 70 Hz. Impedances were maintained at $5 \mathrm{k} \Omega$ or below. Data were obtained using the Nexus 32-Biotrace program and then transformed into ASCII using WinEEG software (Mitsar Ltd. St. Petersburg-Russia), plotted and carefully inspected for manual and automatic artifact rejection. To remove artifacts, an offline EEG analysis was performed using a Common Average Montage and Independent Component Analysis (ICA) was applied to the rejected eye movement and blink artifacts. All episodic artifacts, including muscle artifacts, body movements, and EKG artifacts, were also removed from the stream of EEG by defining a voltage threshold of $100 \mu \mathrm{V}$. "Fast and slow artifact" components were filtered by removing all data exceeding $35 \mu \mathrm{V}$ within the $20-35 \mathrm{~Hz}$ frequency range and all data exceeding $50 \mu \mathrm{V}$ in the $0-1 \mathrm{~Hz}$ range. A 20-minute vigilance-controlled EEG recording with eyes closed alternating with eyes open for 15 seconds every three minutes was carried out. Eight epochs of 2 seconds/minute, totaling 96 epochs or 192 seconds free of artifacts, were selected for each volunteer in the depressed and non-depressed groups for subsequent Fast Fourier Transform (FFT) and also for calculating the Frontal Alpha Asymmetry Index (FAAI).

Frontal Alpha Asymmetry Index (FAAI) is a method of Asymmetry metrics for investigating whether the two brain hemispheres are differentially involved in specific cognitive and affective processes, personality traits, or various forms of psychopathology (Davidson, 1998). The FAAI is an index derived from subtracting the natural logarithm of the left hemisphere power value from the natural logarithm of the right hemisphere power value ( $L n R-L n L)$. The Frontal Alpha Asymmetry Index in this study was obtained by calculating the Fast Fourier Transformation (FFT) and then subtracting the natural logarithm of the Alpha Power in $\mu 2$ in F4 and F8 (right frontal electrodes) from the natural logarithm of the Alpha power in $\mu 2$ in F3 and F7 (let frontal electrodes) (Ln F4 - Ln 
F3; Ln F8 - Ln F7). Because alpha ( $\alpha$ ) power is considered to be inversely related to brain activation, positive numbers or $a>0$ on this index indicate relatively greater left activity, and negative numbers or $\alpha<0$ indicate higher right activity (Davidson, 1998). To compare the FAAI (lognF4-lognF3; lognF8-lognF7) from depressed versus non-depressed patients, a statistical analysis using the t-student was applied.

\subsubsection{Electrodermal Recording}

Electrodermal activity was measured by placing micro-Siemens 1/10,000 high-resolution sensor (Biotrace-Nexus 32) on the middle- and forefinger of the dominant hand of each volunteer. The tonic response or "Skin Conductance Level" was recorded, along with the delay in phasic response, which corresponds to the time elapsing between the tonic stimulus and the peak amplitude of the phasic response provoked (Skin Conductance Response). For each card chosen, the selection time of the samples was divided into two phases, anticipation and a response phase. For the response phase, the first five seconds accompanying the choice was measured. For the anticipation phase, a fluctuating amplitude within the last second before the choice of the next card was selected. For statistical analysis a normalization test was applied, the evaluation of the skin conductance response (SCR's) by group, for each block, was done using the repeated measures ANOVA, comparing non-depressed versus depressed group.

\section{Results}

The characterization data for the sample are presented in (Table 1). The mean score on the Hamilton scale for the depression groups was $29.95 \pm 7.83$, while the score for the non-depressed group was $0.95 \pm 1.27$.

The behavior task using the Iowa Gambling Task (IGT), the depressed group $(\mathrm{D}=-8.85 \pm 16.34, \mathrm{n}=20)$ attained a lower total Net score $(p<0.003)$ than the non-depressed group (ND $=8.7 \pm 11.68, \mathrm{n}=20$ ) (Figure 1 ).

Furthermore, the analysis of the performance of the IGT per block ( 5 blocks of 20 rounds) during the 100 rounds was lower $(p<0.001)$ for the depressed in block $4(\mathrm{D}=1 \pm 9.1$; ND = 3.88 \pm 7.86$)$ and $5(\mathrm{D}=1 \pm 9.8$; ND = $7 \pm 9.4)$ compared with non-depressed (Figure 2).

\section{Electrophysiological Study \\ Analysis of Electrodermal Response}

Evaluation of the skin conductance response (SCR) found that the SCR value for the advantageous cards in blocks $1(\mathrm{D}=2 \pm 1.5 ; \mathrm{ND}=3.1 \pm 1.4)$ and $2(\mathrm{D}=$ $1.6 \pm 1.6 ; \mathrm{ND}=2.6 \pm 1.7)$ was higher $(p<0.05)$ for the non-depressed group. For the disadvantageous cards, the value in blocks $4(\mathrm{D}=1.4 \pm 1.1 ; \mathrm{ND}=2.3 \pm 1.4)$ and $5(\mathrm{D}=1.3 \pm 0.9 ; \mathrm{ND}=2.3 \pm 1.5)$ was found to be higher $(p<0.05)$ for the non-depressed group. The results show better emotional trigger response and learning (somatic marker) in the non-depressed group compared to the depressed individuals (Table 2). 
Table 1. Data characterization.

\begin{tabular}{|c|c|c|}
\hline & Depressed & Depress no Non-depressed \\
\hline$n$ & 20 & 20 \\
\hline Age & $33.8 \pm 10.60 \mathrm{SD}$ & $34.45 \pm 10.53 \mathrm{SD}$ \\
\hline \multicolumn{3}{|l|}{ Gender $(\%)$} \\
\hline Male & $3(15 \%)$ & $11(55 \%)$ \\
\hline Female & $17(85 \%)$ & $9(45 \%)$ \\
\hline \multicolumn{3}{|l|}{ Civil state (\%) } \\
\hline Singer & $6(30 \%)$ & $11(55 \%)$ \\
\hline Married & $10(50 \%)$ & $8(40 \%)$ \\
\hline Other & $4(20 \%)$ & $1(5 \%)$ \\
\hline \multicolumn{3}{|l|}{ Workactivity (\%) } \\
\hline Yes & $16(80 \%)$ & $17(85 \%)$ \\
\hline No & $4(20 \%)$ & $3(15 \%)$ \\
\hline \multicolumn{3}{|l|}{ Familiar history (\%) } \\
\hline Yes & $11(55 \%)$ & $6(30 \%)$ \\
\hline No & $9(45 \%)$ & $14(70 \%)$ \\
\hline \multicolumn{3}{|l|}{ Previouspsychiatricevaluation } \\
\hline Yes & $15(75 \%)$ & $1(5 \%)$ \\
\hline No & $3(15 \%)$ & $14(70 \%)$ \\
\hline Yes, but without a diagnosis & $2(10 \%)$ & $5(25 \%)$ \\
\hline \multicolumn{3}{|l|}{ Previoustreatment (\%) } \\
\hline Yes & $3(15 \%)$ & $2(10 \%)$ \\
\hline No & $17(85 \%)$ & $18(90 \%)$ \\
\hline Yes, justpsychological & $0(0 \%)$ & $0(0 \%)$ \\
\hline \multicolumn{3}{|l|}{ Suicide attempt (\%) } \\
\hline Yes & $3(15 \%)$ & $0(0 \%)$ \\
\hline No & $17(85 \%)$ & $20(100 \%)$ \\
\hline
\end{tabular}

Table 2. Effect of electrodermal response to advantageous and disadvantageous cards per blocks.

\begin{tabular}{cccc}
\hline Play blocks & Cards & Depressed & Non-depressed \\
\hline 1 & Advantageous & $2 \pm 1.5$ & $3.1 \pm 1.4^{\star}$ \\
& Disadvantageous & $2.4 \pm 1.7$ & $3.3 \pm 1.3$ \\
2 & Advantageous & $1.6 \pm 1.6$ & $2.6 \pm 1.7^{*}$ \\
& Disadvantageous & $1.9 \pm 1.7$ & $2.5 \pm 1.6$ \\
3 & Advantageous & $1.5 \pm 1.4$ & $2.5 \pm 1.6$ \\
& Disadvantageous & $1.6 \pm 1.4$ & $2.3 \pm 1.8$ \\
4 & Advantageous & $1.4 \pm 1.2$ & $2.3 \pm 1.7$ \\
& Disadvantageous & $1.4 \pm 1.1$ & $2.3 \pm 1.4^{\star}$ \\
& Advantageous & $1.5 \pm 1.4$ & $2.4 \pm 1.6$ \\
& Disadvantageous & $1.3 \pm 0.9$ & $2.3 \pm 1.5^{*}$ \\
\hline
\end{tabular}

Effect of major depression on the response of the somatic marker (SCR) by playing blocks to advantageous and disadvantageous cards. Repeated measures ANOVA ${ }^{*} p<0.05$. 


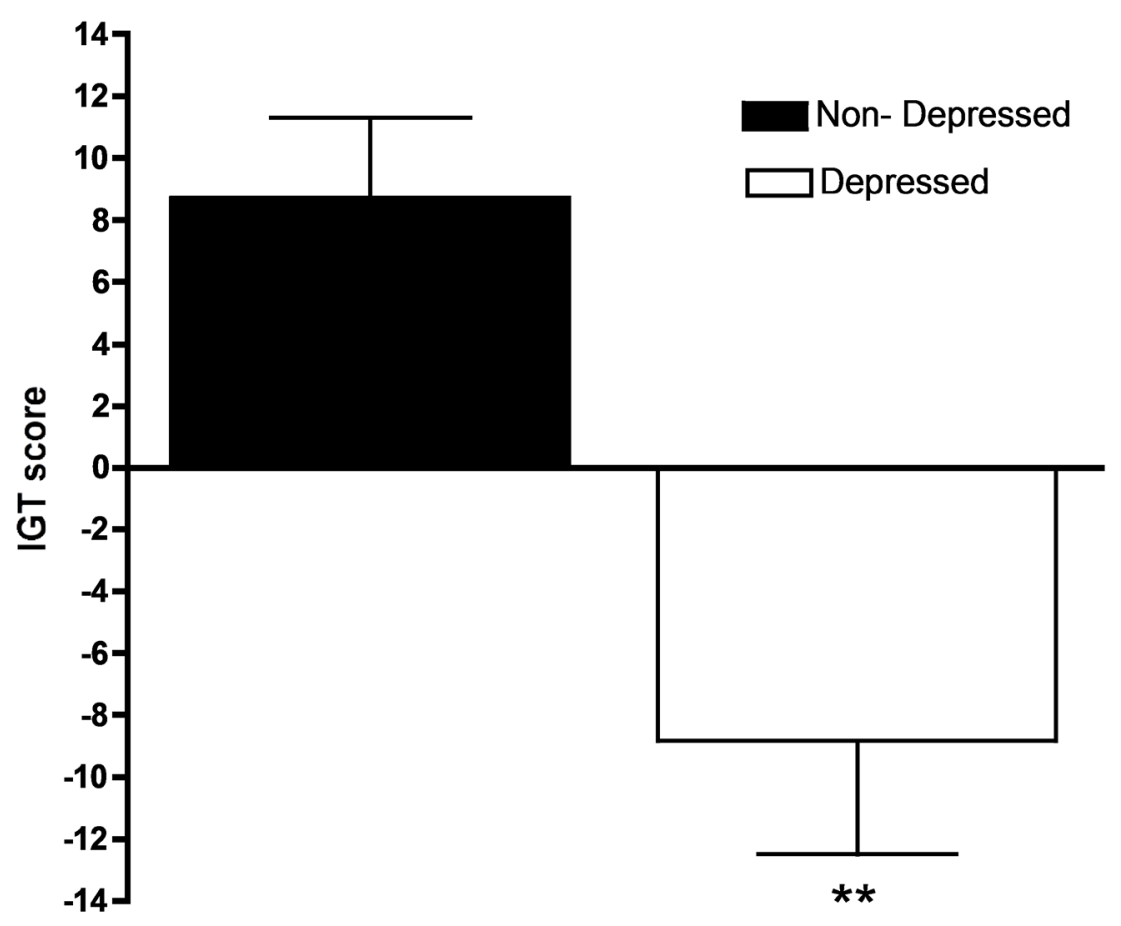

Figure 1. Depressed patients showed a lower total Net score $(p<0.003)$ compared with non-depressed.

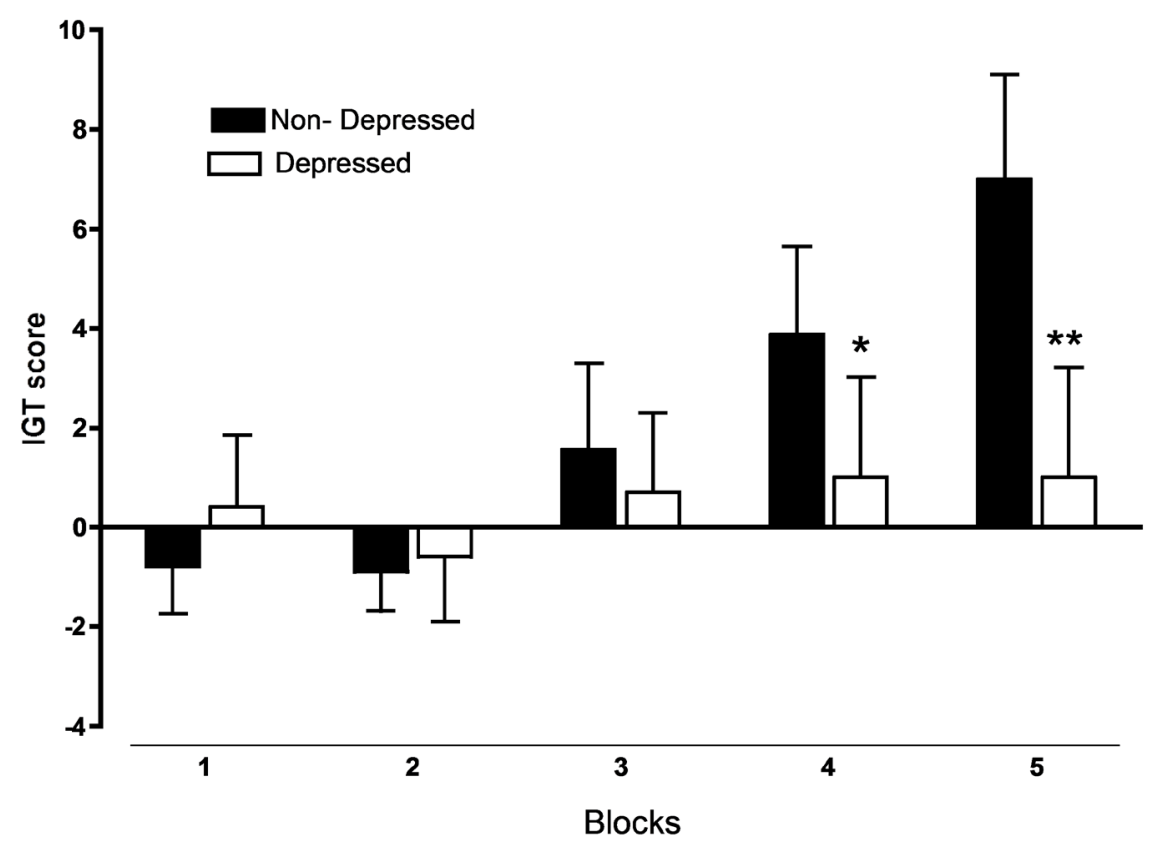

Figure 2. IGT Net score per block showed lower Net score for a depressed group in blocks 4 and 5 with $p<0.001$.

\section{Analysis of Frontal Alpha Asymmetry Index (FAAI)}

The electrophysiological study found that the depressed group exhibited more pronounced activation of the prefrontal cortex (F4 and F8) than the non-depressed group (Figure 3). 


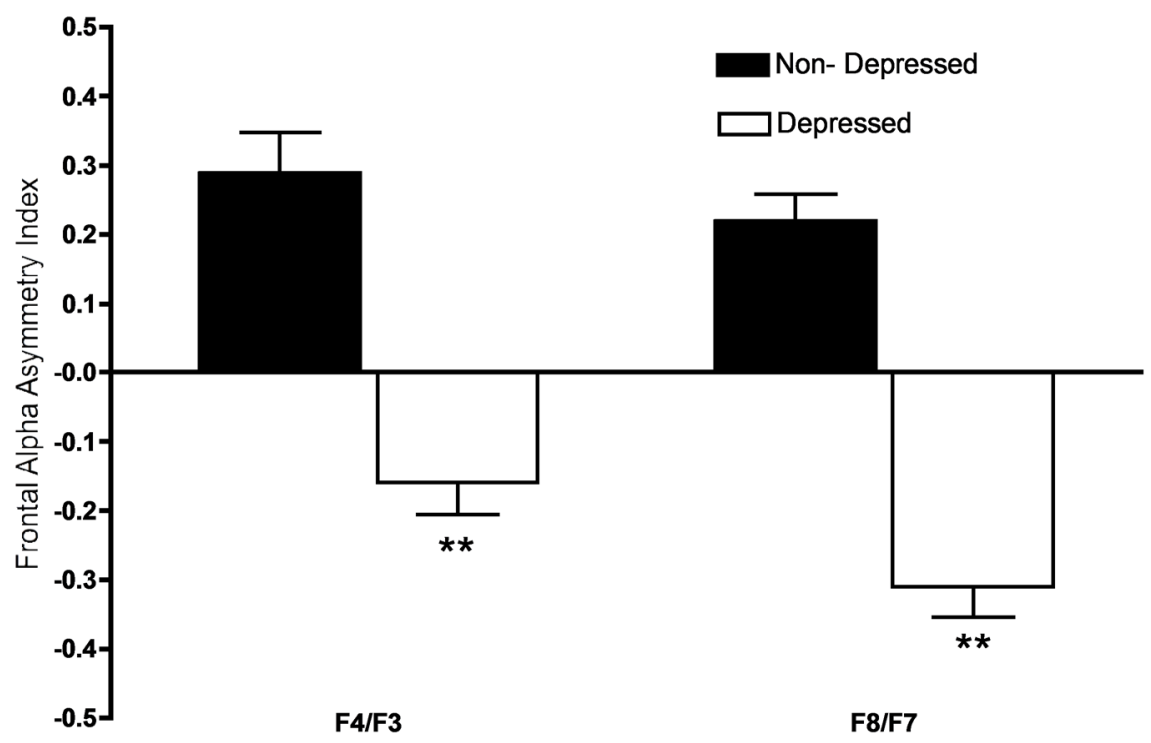

Figure 3. FAAI showed pronounced activation on the right frontal cortex compared to the group of depressed patients with non-depressed patients $(p<0.01)$.

\section{Discussion}

The principal finding of the present study is to stand out that major depression compared with non-depressed patients exhibit impaired in the decision-making risk/punishment during the IGT task associated with a deficit in the anticipatory learning effect. Furthermore, this finding was associated with a more right frontal activation, which has been related to negative emotions (Davidson, 1998; Henriques \& Davidson, 1991, 1997). Major depression affects the flexibility necessary to elaborate on more appropriate strategies and executive planning during decision-making that involves risks and rewards decision-making. In other words, it may suggest that the dysfunction in the socio-emotional monitoring circuit found in major depression may affect the planning and execution of appropriate decision-making.

During the IGT, major depression leads to impaired performance, as measured using the total Net score. Analysis of the Net score per block found that depression considerably reduced the Net score in blocks 4 and 5, showing an impaired learning curve in the course of the game. This result shows that there is an impairment of the circuits related to emotion and decision-making, which alters behavior related to evaluation and judgment of risk in the IGT. It is known that depressed individuals tend to choose advantageous cards with concern for the penalties (Must, Horvath, Nemeth, \& Janka, 2013). According to some authors, the more serious the depression, the poorer the performance on the IGT (Cusi et al., 2012; Must et al., 2013; Takahashi et al., 2008). In the present study, the depressed patients found it difficult to perform effectively throughout the IGT. Analysis of the advantageous cards suggests that there is a difficulty in learning from rewards and a loss of anticipatory effect. It is known that deficiencies in executive functions and attention are considered to be important markers 
of depression (Must et al., 2013; Porter, Bourke, \& Gallagher, 2007).

The EEG/FAAI suggested greater activation of the right frontal cortex (negative emotion) among depressed individuals, as reported in previous studies (Henriques \& Davidson, 1991, 1997). This frontal alpha asymmetry and the poor performance of depressed individuals in the IGT indicates that modulation of the frontal alpha rhythm goes beyond the dimension of affective value (positive emotion = left frontal activation; negative emotion = right frontal activation) and inclines to affect the direction of the modulation of emotions related to decision-making neural circuits (Harmon-Jones \& Allen, 1997).

\section{Final Considerations}

Evaluating decision-making behavior in depressed patients using neurophysiological tools would appear to be a great challenge. In the present study, it was possible to trace a line of reasoning culminating in the grand integration of concepts and ideas that seemed to be separate. However, bringing together the results of various studies that have demonstrated an association between decision-making neural circuits and those related to emotion and cognition sheds much light on the understanding of this complex system.

Further studies comparing patients with major depression undergoing treatment with those untreated would help to understand what kind of therapeutic approach may contribute to regulating and modulating decision-making circuits and improve productive capacity and the ability for strategic planning for more effective decision-making.

\section{Conflicts of Interest}

The authors declare no conflicts of interest regarding the publication of this paper.

\section{References}

Allen, J. J., \& Kline, J. P. (2004). Frontal EEG Asymmetry, Emotion, and Psychopathology: The First, and the Next 25 Years. Biological Psychology, 67, 1-5. https://doi.org/10.1016/j.biopsycho.2004.03.001

Barger, S. D., Messerli-Burgy, N., \& Barth, J. (2014). Social Relationship Correlates of Major Depressive Disorder and Depressive Symptoms in Switzerland: Nationally Representative cross Sectional Study. BMC Public Health, 14, Article No. 273. https://doi.org/10.1186/1471-2458-14-273

Bechara, A., \& Van Der Linden, M. (2005). Decision-Making and Impulse Control after Frontal Lobe Injuries. Current Opinion in Neurology, 18, 734-739. https://doi.org/10.1097/01.wco.0000194141.56429.3c

Bechara, A., Damasio, H., Tranel, D., \& Damasio, A. R. (2005). The Iowa Gambling Task and the Somatic Marker Hypothesis: Some Questions and Answers. Trends in Cognitive Sciences, 9, 159-162; Discussion 162-154. https://doi.org/10.1016/j.tics.2005.02.002

Bechara, A., Tranel, D., \& Damasio, H. (2000). Characterization of the Decision-Making Deficit of Patients with Ventromedial Prefrontal Cortex Lesions. Brain, 123, 2189-2202. https://doi.org/10.1093/brain/123.11.2189 
Beitz, K. M., Salthouse, T. A., \& Davis, H. P. (2014). Performance on the Iowa Gambling Task: From 5 to 89 Years of Age. Journal of Experimental Psychology: General, 143, 1677-1689. https://doi.org/10.1037/a0035823

Bollon, T., \& Bagneux, V. (2013). Can the Uncertainty Appraisal Associated with Emotion Cancel the Effect of the Hunch Period in the Iowa Gambling Task? Cognition and Emotion, 27, 376-384. https://doi.org/10.1080/02699931.2012.712947

Coan, J. A., Allen, J. J., \& McKnight, P. E. (2006). A Capability Model of Individual Differences in Frontal EEG Asymmetry. Biological Psychology, 72, 198-207. https://doi.org/10.1016/j.biopsycho.2005.10.003

Costello, E. J. (1983). Information Processing for Decision Making in Depressed Women. A Study of Subjective Expected Utilities. Journal of Affective Disorders, 5, 239-251. https://doi.org/10.1016/0165-0327(83)90047-2

Cotrena, C., Branco, L. D., Zimmermann, N., Cardoso, C. O., Grassi-Oliveira, R., \& Fonseca, R. P. (2014). Impaired Decision-Making after Traumatic Brain Injury: The Iowa Gambling Task. Brain Injury, 28, 1070-1075. https://doi.org/10.3109/02699052.2014.896943

Cui, J. F., Chen, Y. H., Wang, Y., Shum, D. H., \& Chan, R. C. (2013). Neural Correlates of Uncertain Decision Making: ERP Evidence from the Iowa Gambling Task. Frontiers in Human Neuroscience, 7, 776. https://doi.org/10.3389/fnhum.2013.00776

Cusi, A. M., Nazarov, A., Holshausen, K., Macqueen, G. M., \& McKinnon, M. C. (2012). Systematic Review of the Neural Basis of Social Cognition in Patients with Mood Disorders. Journal of Psychiatry \& Neuroscience, 37, 154-169.

Damasio, H., Grabowski, T., Frank, R., Galaburda, A. M., \& Damasio, A. R. (1994). The Return of Phineas Gage: Clues about the Brain from the Skull of a Famous Patient. Science, 264, 1102-1105. https://doi.org/10.1126/science.8178168

Davidson, R. J. (1992). Anterior Cerebral Asymmetry and the Nature of Emotion. Brain and Cognition, 20, 125-151. https://doi.org/10.1016/0278-2626(92)90065-T

Davidson, R. J. (1998). Anterior Electrophysiological Asymmetries, Emotion, and Depression: Conceptual and Methodological Conundrums. Psychophysiology, 35, 607-614. https://doi.org/10.1017/S0048577298000134

Davidson, R. J., Chapman, J. P., Chapman, L. J., \& Henriques, J. B. (1990). Asymmetrical Brain Electrical Activity Discriminates between Psychometrically-Matched Verbal and Spatial Cognitive Tasks. Psychophysiology, 27, 528-543.

https://doi.org/10.1111/j.1469-8986.1990.tb01970.x

Denburg, N. L., Tranel, D., \& Bechara, A. (2005). The Ability to Decide Advantageously Declines Prematurely in Some Normal Older Persons. Neuropsychologia, 43, 1099-1106. https://doi.org/10.1016/j.neuropsychologia.2004.09.012

Drevets, W. C. (1999). Prefrontal Cortical-Amygdalar Metabolism in Major Depression. Annals of the New York Academy of Sciences, 877, 614-637. https://doi.org/10.1111/j.1749-6632.1999.tb09292.x

Drevets, W. C. (2001). Neuroimaging and Neuropathological Studies of Depression: Implications for the Cognitive-Emotional Features of Mood Disorders. Current Opinion in Neurobiology, 11, 240-249. https://doi.org/10.1016/S0959-4388(00)00203-8

Drevets, W. C. (2003). Neuroimaging Abnormalities in the Amygdala in Mood Disorders. Annals of the New York Academy of Sciences, 985, 420-444. https://doi.org/10.1111/j.1749-6632.2003.tb07098.x

Drevets, W. C. (2007). Orbitofrontal Cortex Function and Structure in Depression. Annals of the New York Academy of Sciences, 1121, 499-527.

https://doi.org/10.1196/annals.1401.029 
Drevets, W. C., \& Raichle, M. E. (1992). Neuroanatomical Circuits in Depression: Implications for Treatment Mechanisms. Psychopharmacology Bulletin, 28, 261-274.

Drevets, W. C., Bogers, W., \& Raichle, M. E. (2002). Functional Anatomical Correlates of Antidepressant Drug Treatment Assessed Using PET Measures of Regional Glucose Metabolism. European Neuropsychopharmacology, 12, 527-544.

https://doi.org/10.1016/S0924-977X(02)00102-5

Drevets, W. C., Price, J. L., \& Furey, M. L. (2008). Brain Structural and Functional Abnormalities in Mood Disorders: Implications for Neurocircuitry Models of Depression. Brain Structure \& Function, 213, 93-118. https://doi.org/10.1007/s00429-008-0189-x

Drevets, W. C., Savitz, J., \& Trimble, M. (2008). The Subgenual Anterior Cingulate Cortex in Mood Disorders. CNS Spectrums, 13, 663-681. https://doi.org/10.1017/S1092852900013754

Fellows, L. K., \& Farah, M. J. (2007). The Role of Ventromedial Prefrontal Cortex in Decision Making: Judgment under Uncertainty or Judgment per se? Cerebral Cortex, 17, 2669-2674. https://doi.org/10.1093/cercor/bhl176

First, M. B., Spitzer, R. L., Gibbon, M., \& Williams, J. B. W. (1997). Structured Clinical Interview for DSM-IV Axis I Disorders-Clinician Version (SCID-CV) (p. 84). Washington DC: American Psychiatric Press.

Gavin, A. R., Walton, E., Chae, D. H., Alegria, M., Jackson, J. S., \& Takeuchi, D. (2010). The Associations between Socio-Economic Status and Major Depressive Disorder among Blacks, Latinos, Asians and Non-Hispanic Whites: Findings from the Collaborative Psychiatric Epidemiology Studies. Psychological Medicine, 40, 51-61.

https://doi.org/10.1017/S0033291709006023

Greene, J. D., \& Paxton, J. M. (2009). Patterns of Neural Activity Associated with Honest and Dishonest Moral Decisions. Proceedings of the National Academy of Sciences of the United States of America, 106, 12506-12511.

https://doi.org/10.1073/pnas.0900152106

Greene, J. D., Nystrom, L. E., Engell, A. D., Darley, J. M., \& Cohen, J. D. (2004). The Neural Bases of Cognitive Conflict and Control in Moral Judgment. Neuron, 44, 389-400. https://doi.org/10.1016/j.neuron.2004.09.027

Hamilton, M. (1960). A Rating Scale for Depression. Journal of Neurology, Neurosurgery and Psychiatry, 23, 56-62. https://doi.org/10.1136/jnnp.23.1.56

Hamilton, M. (1967). Development of a Rating Scale for Primary Depressive Illness. British Journal of Social and Clinical Psychology, 6, 278-296. https://doi.org/10.1111/j.2044-8260.1967.tb00530.x

Harle, K. M., Allen, J. J., \& Sanfey, A. G. (2010). The Impact of Depression on Social Economic Decision Making. Journal of Abnormal Psychology, 119, 440-446.

https://doi.org/10.1037/a0018612

Harmon-Jones, E., \& Allen, J. J. (1997). Behavioral Activation Sensitivity and Resting Frontal EEG Asymmetry: Covariation of Putative Indicators Related to Risk for Mood Disorders. Journal of Abnormal Psychology, 106, 159-163.

https://doi.org/10.1037/0021-843X.106.1.159

Harmon-Jones, E., \& Allen, J. J. (1998). Anger and Frontal Brain Activity: EEG Asymmetry Consistent with Approach Motivation Despite Negative Affective Valence. Journal of Personality and Social Psychology, 74, 1310-1316. https://doi.org/10.1037/0022-3514.74.5.1310

Henriques, J. B., \& Davidson, R. J. (1990). Regional Brain Electrical Asymmetries Discriminate between Previously Depressed and Healthy Control Subjects. Journal of $A b$ normal Psychology, 99, 22-31. https://doi.org/10.1037/0021-843X.99.1.22 
Henriques, J. B., \& Davidson, R. J. (1991). Left Frontal Hypoactivation in Depression. Journal of Abnormal Psychology, 100, 535-545. https://doi.org/10.1037/0021-843X.100.4.535

Henriques, J. B., \& Davidson, R. J. (1997). Brain Electrical Asymmetries during Cognitive Task Performance in Depressed and Nondepressed Subjects. Biological Psychiatry, 42, 1039-1050. https://doi.org/10.1016/S0006-3223(97)00156-X

Henriques, J. B., Glowacki, J. M., \& Davidson, R. J. (1994). Reward Fails to Alter Response Bias in Depression. Journal of Abnormal Psychology, 103, 460-466. https://doi.org/10.1037/0021-843X.103.3.460

Holmes, A. J., \& Pizzagalli, D. A. (2008). Response Conflict and Frontocingulate Dysfunction in Unmedicated Participants with Major Depression. Neuropsychologia, 46, 2904-2913. https://doi.org/10.1016/j.neuropsychologia.2008.05.028

Jaracz, M., \& Borkowska, A. (2012). [Iowa Gambling Task-Tool for Assessment of Decision Making]. Psychiatria Polska, 46, 461-472.

Levin, I. P., Xue, G., Weller, J. A., Reimann, M., Lauriola, M., \& Bechara, A. (2012). A Neuropsychological Approach to Understanding Risk-Taking for Potential Gains and Losses. Frontiers in Neuroscience, 6, 15. https://doi.org/10.3389/fnins.2012.00015

Li, X., Lu, Z. L., D’Argembeau, A., Ng, M., \& Bechara, A. (2010). The Iowa Gambling Task in fMRI Images. Human Brain Mapping, 31, 410-423. https://doi.org/10.1002/hbm.20875

McLaughlin, K. A. (2011). The Public Health Impact of Major Depression: A Call for Interdisciplinary Prevention Efforts. Prevention Science, 12, 361-371.

https://doi.org/10.1007/s11121-011-0231-8

Must, A., Horvath, S., Nemeth, V. L., \& Janka, Z. (2013). The Iowa Gambling Task in Depression-What Have We Learned about Sub-Optimal Decision-Making Strategies? Frontiers in Psychology, 4, 732. https://doi.org/10.3389/fpsyg.2013.00732

Nauta, W. J., \& Domesick, V. B. (1984). Afferent and Efferent Relationships of the Basal Ganglia. In D. Evered, \& M. O’Connor (Eds.), Ciba Foundation Symposium 107 (pp. 3-29). Hoboken, NJ: John Wiley \& Sons, Inc. https://doi.org/10.1002/9780470720882.ch2

Ongur, D., Ferry, A. T., \& Price, J. L. (2003). Architectonic Subdivision of the Human Orbital and Medial Prefrontal Cortex. Journal of Comparative Neurology, 460, 425-449. https://doi.org/10.1002/cne.10609

Pizzagalli, D. A. (2011). Frontocingulate Dysfunction in Depression: Toward Biomarkers of Treatment Response. Neuropsychopharmacology, 36, 183-206. https://doi.org/10.1038/npp.2010.166

Pizzagalli, D. A., Iosifescu, D., Hallett, L. A., Ratner, K. G., \& Fava, M. (2008). Reduced Hedonic Capacity in Major Depressive Disorder: Evidence from a Probabilistic Reward Task. Journal of Psychiatric Research, 43, 76-87.

https://doi.org/10.1016/j.jpsychires.2008.03.001

Pizzagalli, D. A., Peccoralo, L. A., Davidson, R. J., \& Cohen, J. D. (2006). Resting Anterior Cingulate Activity and Abnormal Responses to Errors in Subjects with Elevated Depressive Symptoms: A 128-Channel EEG Study. Human Brain Mapping, 27, 185-201. https://doi.org/10.1002/hbm.20172

Porter, R. J., Bourke, C., \& Gallagher, P. (2007). Neuropsychological Impairment in Major Depression: Its Nature, Origin and Clinical Significance. Australian \& New Zealand Journal of Psychiatry, 41, 115-128. https://doi.org/10.1080/00048670601109881

Price, J. L. (2007). Definition of the Orbital Cortex in Relation to Specific Connections 
with Limbic and Visceral Structures and Other Cortical Regions. Annals of the New York Academy of Sciences, 1121, 54-71. https://doi.org/10.1196/annals.1401.008

Radford, M. H., Nakane, Y., Ohta, Y., Mann, L., \& Kalucy, R. S. (1991). Decision Making in Clinically Depressed Patients. A Transcultural Social Psychological Study. The Journal of Nervous and Mental Disease, 179, 711-719. https://doi.org/10.1097/00005053-199112000-00001

Schaffer, C. E., Davidson, R. J., \& Saron, C. (1983). Frontal and Parietal Electroencephalogram Asymmetry in Depressed and Nondepressed Subjects. Biological Psychiatry, 18, 753-762.

Steingroever, H., \& Wagenmakers, E. J. (2014). Performance and Awareness in the Iowa Gambling Task. Behavioral and Brain Sciences, 37, 41-42.

https://doi.org/10.1017/S0140525X13000861

Stewart, J. L., Bismark, A. W., Towers, D. N., Coan, J. A., \& Allen, J. J. (2010). Resting Frontal EEG Asymmetry as an Endophenotype for Depression Risk: Sex-Specific Patterns of Frontal Brain Asymmetry. Journal of Abnormal Psychology, 119, 502-512. https://doi.org/10.1037/a0019196

Stewart, J. L., Coan, J. A., Towers, D. N., \& Allen, J. J. (2011). Frontal EEG Asymmetry during Emotional Challenge Differentiates Individuals with and without Lifetime Major Depressive Disorder. Journal of Affective Disorders, 129, 167-174.

https://doi.org/10.1016/j.jad.2010.08.029

Sutton, S. K., \& Davidson, R. J. (2000). Prefrontal Brain Electrical Asymmetry Predicts the Evaluation of Affective Stimuli. Neuropsychologia, 38, 1723-1733. https://doi.org/10.1016/S0028-3932(00)00076-2

Takahashi, T., Oono, H., Inoue, T., Boku, S., Kako, Y., Kitaichi, Y. et al. (2008). Depressive Patients Are More Impulsive and Inconsistent in Intertemporal Choice Behavior for Monetary Gain and Loss than Healthy Subjects-An Analysis Based on Tsallis' Statistics. Neuro Enocrinology Letters, 29, 351-358.

Tomarken, A. J., Davidson, R. J., \& Henriques, J. B. (1990). Resting Frontal Brain Asymmetry Predicts Affective Responses to Films. Journal of Personality and Social Psychology, 59, 791-801. https://doi.org/10.1037/0022-3514.59.4.791

Tomarken, A. J., Davidson, R. J., Wheeler, R. E., \& Doss, R. C. (1992). Individual Differences in Anterior Brain Asymmetry and Fundamental Dimensions of Emotion. Journal of Personality and Social Psychology, 62, 676-687. https://doi.org/10.1037/0022-3514.62.4.676

Van Randenborgh, A., de Jong-Meyer, R., \& Huffmeier, J. (2010). Decision Making in Depression: Differences in Decisional Conflict between Healthy and Depressed Individuals. Clinical Psychology \& Psychotherapy, 17, 285-298.

https://doi.org/10.1002/cpp.651

Zhang, H. J., Sun, D., \& Lee, T. M. (2012). Impaired Social Decision Making in Patients with Major Depressive Disorder. Brain and Behavior, 2, 415-423. https://doi.org/10.1002/brb3.62

Zoon, H. F., Veth, C. P., Arns, M., Drinkenburg, W. H., Talloen, W., Peeters, P. J., \& Kenemans, J. L. (2013). EEG Alpha Power as an Intermediate Measure between Brain-Derived Neurotrophic Factor Val66Met and Depression Severity in Patients with Major Depressive Disorder. Journal of Clinical Neurophysiology, 30, 261-267. https://doi.org/10.1097/WNP.0b013e3182933d6e 